\title{
Interactive effects of interpellet interval and pellet composition on schedule-induced licking and drinking behavior
}

\author{
WALTER P. CHRISTIAN \\ Auburn University, Auburn, Alabama 36830
}

\begin{abstract}
Three groups of rats received different formulae of Noyes 45-mg dry food pellets (sugarless, $7.5 \%$ sucrose, $7.5 \%$ glucose) on fixed time reinforcement schedules with interpellet intervals of 30,60 , and 90 sec. For all groups, as interpellet interval increased, water consumed and licks per session increased to a maximum and then decreased. Licks per pellet increased across sessions. There was a significant interaction between pellet formula and interpellet interval. The type of sugar contained in the food pellet affected the number of licks and the number of mls consumed.
\end{abstract}

The development of schedule-induced polydipsia (Falk, 1961) is influenced by the size (Falk, 1967; Flory, 1971), spacing (Falk, 1966; Flory, 1971; Segal, Oden, \& Deadwyler, 1965), and composition (Burks, Hitzing, \& Schaeffer, 1967; Christian \& Schaeffer, $1973 \mathrm{~b}$; Falk, 1967) of the dry food reinforcers given food-deprived rats under response-contingent and response-independent scheduling conditions. In addition, the composition of dry food reinforcement and interpellet interval have been frequently manipulated in attempts to arrive at a definitive explanation for schedule-induced polydipsia. Major theoretical explanations have viewed the phenomenon as resulting from thirst (Stein, 1964), adventitious reinforcement (Clark, 1962), consummatory rate (Falk, 1969; Flory, 1971), adjunctive behavior (Falk, 1966), and motivational, aversive, or frustrative factors (Denny \& Ratner, 1970; Hymowitz, 1973).

The present experiment investigated whether the composition of dry food reinforcement and the fixed-time (FT) interpellet interval interact in their effects on licking and water intake of food-deprived rats. Previous findings (King, 1974) have indicated the additive effects of food deprivation, interpellet interval, and electric shock upon schedule-induced polydipsia, but the possible relationship between interpellet interval and pellet composition as they affect schedule-induced licking and drinking has not been examined.

\section{METHOD}

\section{Subjects}

Subjects were 12 experimentally naive female albino

These data are based on a portion of a dissertation submitted to the Department of Psychology, Auburn University, in partial fulfillment of the requirements of $\mathrm{PhD}$ degree. I wish to thank R. W. Schaeffer for his advise and support during the course of this study. This paper is sponsored by T. L. Creer, who takes full editorial responsibility for it.

The author is presently at Behavior Science Division, CARIH: The National Asthma Center, 1999 Julian Street, Denver, Colorado 80204.
Sprague-Dawley rats, approximately 120 to 150 days old at the beginning of the experiment. They had water freely available in the home cage and in the test chambers throughout the entire experiment.

\section{Apparatus}

Three LVE Model 1316 experimental chambers were used. In each chamber, the right lever was removed to permit insertion of the spout of the drinking tube. The tip of the drinking spout, slightly recessed behind a plastic collar used to position the spout in standard position, was located $7 \mathrm{~cm}$ to the right of the food cup and $3.5 \mathrm{~cm}$ from the floor of the chamber. Responses were recorded and food pellets were delivered automatically by standard relay circuitry. Licks and pellet deliveries were recorded on Gerbrands cumulative recorders and on an Esterline-Angus digital operations recorder. Water intake during the experimental sessions was obtained by weighing the water bottles before and after each session.

\section{Procedure}

The 12 subjects were randomly assigned to three groups of four subjects each. Group 1 received Noyes $45-\mathrm{mg}$ sugarless pellets (Christian \& Schaeffer, 1973a) during experimental sessions; Group 2 received Noyes $45-\mathrm{mg}$ sugarless pellets with $7.5 \%$ sucrose added by weight; and Group 3 received Noyes 45 -mg standard formula pellets, which contain $7.5 \%$ glucose by weight.

The experiment had 5 phases: (1) baseline; (2) FT 30-sec; (3) FT 60-sec; (4) FT 90-sec; and (5) baseline. Before the experiment started, all animals were given Purina pelleted lab chow ad lib in the home cage, with water freely available. The subjects were then reduced to and maintained at $85 \%$ of those free-feeding weights by supplementing pellets obtained in the test chamber with Purina pelleted lab chow given in the home cage following each session.

Each of the experimental phases was continued until the stability criterion employed (Schoenfeld, Cumming, \& Hearst, 1956) indicated that, for the last six sessions of any phase, the difference between the mean intakes of the first three sessions and the last three was less than $10 \%$ of the overall mean for all six sessions.

During the baseline phase, all food was removed from the home cage, with water remaining freely available. Subjects remained in the experimental chamber for $100 \mathrm{~min}$ each session throughout this and all later phases. Each baseline session began with 100 pellets of the appropriate Noyes formula in the food cup. This phase continued until water intakes in the test 


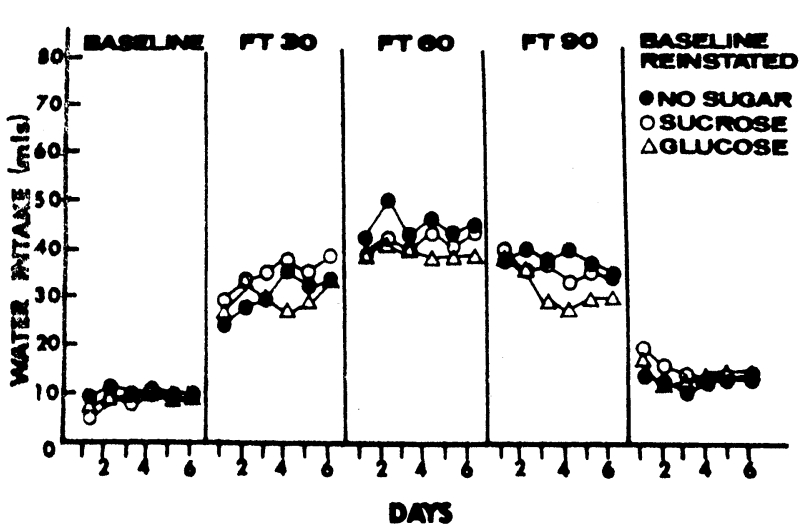

Figure 1. Mean session water intakes for each pellet formula group over the experiment.

chamber stabilized and the subjects regularly ate all 100 pellets in the food cup within the allotted session time.

In Phases 2-4, all rats received pellets of the appropriate Noyes formula on a FT 30-sec, FT 60-sec, and FT 90-sec schedule, in that order. Phase 5 reinstated the baseline condition. There are several criteria for determining the degree of polydipsia (Falk, 1969); in the present study, polydipsia was defined conservatively as the fixed-time interval at which mean session intake was at least twice the original mean baseline intake.

\section{RESULTS}

Figure 1 presents mean water intakes in the test chamber for the last six sessions of each phase of the experiment. Home cage intakes were of the same low magnitude as has been consistently reported in previous schedule-induced polydipsia research (cf. Falk, 1961). Figure 1 indicates that subjects in each of the three formula groups became polydipsic during the FT 30-sec condition and remained polydipsic throughout the $60-\mathrm{sec}$ and $90-\mathrm{sec}$ conditions. Intakes were maximum during the 60-sec condition, were lower during the 30 -sec and 90-sec conditions, and were lowest during baseline conditions.

Differences among mean session intakes of the formula groups were clearest during the $60-\mathrm{sec}$ condition. Highest intakes were obtained for the sugarless formula group, followed by the $7.5 \%$ sucrose and $7.5 \%$ glucose groups, respectively, although the difference between groups was not statistically significant.

Figure 2 presents mean licks per group during each experimental condition. During FT $60-\mathrm{sec}$, the sugarless group licked more than either of the groups receiving sugared pellets. The results of a repeated-measure analysis of variance applied to the lick-per-session data indicated a statistically significant difference among fixed-time schedules $(\mathrm{F}=21.35 ; \mathrm{df}=2,18 ; \mathrm{p}<.001)$ as well as a significant interaction between pellet formula and fixed-time schedule $(F=15.48 ; \mathrm{df}=4,18$; $\mathrm{p}<.001)$.

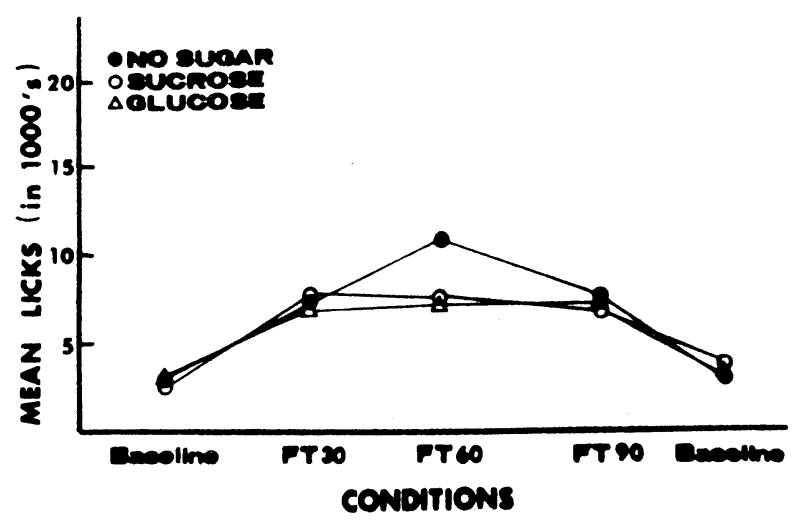

Figure 2. Mean licks emitted by each group during each experimental session.

Since the number of pellets delivered per 100-min session varied with interpellet interval, but equally for all groups, the number of licks per pellet was also analyzed. Licks per pellet increased for each group across sessions. A repeated measures analysis of variance applied to the licks-per-pellet data revealed a statistically significant difference among fixed-time schedules $(\mathrm{F}=114.57 ; \mathrm{df}=$ $2,18 ; \mathrm{p}<.001)$ and a significant interaction between pellet formula and fixed time schedules $(\mathrm{F}=2.94 ; \mathrm{df}=$ $4,18 ; \mathrm{p}<.05)$. The difference among formula groups was not statistically significant.

\section{DISCUSSION}

All subjects were polydipsic during the fixed-time schedules relative to their continuous-feeding baseline water intakes. Intake data support previous findings by Segal et al. (1965) that the functions between fixed-time interval and water consumption and between fixed-time interval and licks by food-deprived rats are bitonic. Segal et al. (1965), using Noyes 45-mg peanut-formula pellets, found that maximum intakes were generated by a 120 -sec fixed-time interval in a 30 - to 480 -sec interval series. Maximum intakes in the present study, however, were generated by FT $60-\mathrm{sec}$ in a $30-$ to $90-\mathrm{sec}$ series, using Noyes 45-mg sugarless, $7.5 \%$ sucrose- and glucose-formula pellets. The differences between these findings would seem to offer further support for the interactive relationship of pellet formula and interpellet interval observed in the present study.

The present findings confirm previous observations that removing sugar from dry food pellets increases licking and water intake on fixed-time schedules (Christian \& Schaeffer, 1973b) and lick-contingent fixed-ratio schedules (Christian et al., 1973). In the present study, during the FT 60 -sec, rats receiving sugarless food pellets licked more than rats receiving either of the sugar-formula pellets. These data also offer new evidence that the type of sugar in the dry food pellet (sucrose, glucose) affects licking and drinking although the quantity of each sugar in the food pellet is held constant.

These findings, therefore, have demonstrated the interactive effect of the composition of dry food reinforcement and interpellet interval upon licks emitted on fixed-time schedules by food-deprived rats. Such a relationship exists for licks per session as well as licks per pellet received during fixed-time schedules. Investigators should take note of these interaction effects when designing research in the area of schedule-induced polydipsia. 


\section{REFERENCES}

Burks, C. D., Hitzing, E. W., \& Schaeffer, R. W. Drinking response distributions associated with a $4 \%$ sucrose FFI food schedule. Psychonomic Science, 1967, 8, 13-14.

Christian, W. P., Jr., \& Schaeffer, R. W. Note: Advisability of using sugar-free food pellets for schedule-induced polydipsia research. Psychological Reports, 1973a, 32, 274.

Christian, W. P., Jr., \& Schaeffer, R. W. Effects of sucrose concentrations upon schedule-induced polydipsia on a FF1-60-sec dry-food reinforcement schedule. Psychological Reports, 1973b, 32, 1067-1073.

Christian, W. P., Jr., Reister, R. W., \& Schaeffer, R. W. Effects of sucrose concentrations upon schedule-induced polydipsia using free and response-contingent dry-food reinforcement schedules. Bulletin of the Psychonomic Society, 1973, 2, 65-68.

Clark, F. C. Some observations on the adventitious reinforcement of drinking under food reinforcement. Journal of the Experimental Analysis of Behavior, 1962, 6, 61-63.

Denny, M. R., \& Ratner, S. C. Comparative psychology. Homewood, Illinois: Dorsey, 1970.

Falk, J. L. Production of polydipsia in normal rats by an intermitten food schedule. Science, 1961, 133, 195-196.

Falk, J. L. Schedule-induced polydipsia as a function of fixed-interval length. Journal of the Experimental Analysis of Behavior, 1966, 9, 37-39.
Falk, J. L. Control of schedule-induced polydipsia: type, size and spacing of meals. Journal of Experimental Analysis of Behavior, 1967, 10, 199-206.

Falk, J. L. Conditions producing psychogenic polydipsia in animals. Annals of the New York Academy of Sciences, 1969, $157,569,593$.

Flory, R. K. The control of schedule-induced polydipsia: Frequency and magnitude of reinforcement. Learning and Motivation, 1971, 2, 215-227.

Hymowitz, N. Effects of lever-press dependent and independent electric shock on schedule-induced water intake. The Psychological Record, 1973, 23, 487-497.

King, G. D. The enhancement of schedule-induced polydipsia by preschedule noncontingent shock. Bulletin of the Psychonomic Society, 1974, 3, 46-48.

Schoenfeld, W. N., Cumming, W. W., \& Hearst, E. On the classification of reinforcement schedules. Proceedings of the National Academy of Sciences, 1956, 42, 563-570.

Segal, E. F., Oden, D. L. \& Deadwyler, S. A. Determinants of polydipsia: IV. Free-reinforcement schedules. Psychonomic Science, 1965, 3, 11-12.

Stein, L. Excessive drinking in the rat: Superstition or thirst? Journal of Comparative and Physiological Psychology, 1964,
58, 237-242.

(Received for publication October 17, 1974.)

\title{
Stimulus distinctiveness and backward associations
}

\author{
DONALD G. WILDEMANN \\ University of North Carolina at Greensboro, Greensboro, North Carolina 27412
}

\begin{abstract}
In two paired-associate experiments, one stimulus was made a distinctive item by making this stimulus a different color from all other items. In subsequent backward-association tests, the distinctive stimulus was emitted as a correct backward association significantly more frequently than other items. In other analyses, the number of correct forward anticipations was computed for each of the nondistinctive pairs and used as a measure of forward associative strength. These analyses showed that stimulus distinctiveness produced a greater effect on backward associations than did forward associative strength. For the nondistinctive pairs, the correlation between the number of correct forward anticipations and the subsequent probability of a correct backward association accounted for less than $6 \%$ of the variance.
\end{abstract}

Most theories of transfer in human paired-associate (PA) learning have proposed that backward associations are a major source of facilitation or interference in transfer (e.g., Kausler, 1974; Merryman, 1971; Postman \& Stark, 1972). An implicit assumption in these theories is that the "strength" of a backward association should vary directly with the strength of the forward association. Since this assumption has rarely, if ever, been directly tested, one purpose of the following

This research was supported by a grant from the Research Council of the University of North Carolina at Greensboro (RCG-605). This paper is sponsored by Robert E. Eason, who takes full editorial responsibility for it. Requests for reprints should be sent to Donald G. Wildemann, Department of Psychology, University of North Carolina at Greensboro, Greensboro, North Carolina 27412. experiments was to provide such a test.

A second purpose of the present study was to contrast the relative effect of stimulus characteristics and the relative effect of forward associative strength on backward associations. Numerous experiments using both infrahuman and human subjects have demonstrated that only part of the experimental stimuli may control a subject's behavior (cf., Kintsch, 1970; Sutherland \& Mackintosh, 1971). As several investigators have noted (e.g., Ekstrand, 1966), if the stimulus actually controlling a subject's behavior (i.e., the functional stimulus) differs from the stimulus presented by the experimenter (i.e., the nominal stimulus), any decrements in the recall of the backward association could be due to this difference. It may, however, be 